\title{
Dendritic cells and their relation to apical peridontitis
}

\author{
José Antonio Poli de FIGUEIREDO(a) \\ Audrey Moraes MACHADO(b) \\ Vinícius Pasqualotti de OLIVEIRA ${ }^{(b)}$ \\ Rafael HARTMANN(b) \\ Silvana Beltrami Gonçalves \\ WALTRICK(b) \\ Maristela Gutierrez de BORBA ${ }^{(b)}$ \\ Myrian Câmara BREW(c) \\ Cyntia Rodrigues de Araújo \\ ESTRELA ${ }^{(d)}$ \\ Daiana Elisabeth BÖTTCHER(b)
}

(a) Universidade Federal do Rio Grande do Sul - UFRGS, School of Dentistry, Department of Morphological Sciences, Porto Alegre, RS, Brazil.

(b) Pontifícia Universidade Católica do Rio Grande do Sul - PUCRS, School of Dentistry, Clinical Department, Porto Alegre, RS, Brazil.

(c) Universidade Luterana do Brasil - ULBRA, Canoas, RS, Brazil.

(d) Universidade de Cuiabá - UNIC, School of Dentistry, Cuiabá, MT, Brazil.

Declaration of Interests: The authors certify that they have no commercial or associative interest that represents a conflict of interest in connection with the manuscript.

\section{Corresponding Author:}

José Antonio Poli de Figueiredo

E-mail: jose.figueiredo@pucrs.br

hHtps://doi.org/10.1590/1807-3107BOR-2018.vol32.0071

Submitted: May 06, 2018

Accepted for publication: May 29, 2018

Last revision: June 07, 2018
Abstract: The purpose of this manuscript was to re-discuss apical periodontitis, apical biofilm, and its possible relationship with dendritic cells (DC). DCs are potent regulators of the immune system and their function is divided into three categories that involve the presentation of antigens: the presentation of antigens and activation of T cells; a not well established category suggested that DCs induce and maintain immunological tolerance; and the maintenance of the immune memory in conjunction with B cells. DCs in periapical inflammatory lesions are composed of at least two subpopulations that can be distinguished on the basis of ultrastructure and phenotype. These populations might differ in lineage, state of maturation, differentiation, activation, and/or function. The authors hereby analyzed the root apexes of teeth under SEM, after performing apicoectomy due to the failure of conventional endodontic treatment. Microbial biofilm with multispecies and areas of resorption with the presence of Howship lacunae, and images suggestive of denditric cells could be observed. The presence of DCs in periapical lesion could be an indication of the severity of the lesion, with a constant presence of antigen in the periradicular region.

Keywords: Dendritic Cells; Periapical Periodontitis; Apicoectomy; Biofilms.

\section{Introduction}

Apical periodontitis is characterized by an inflammatory process that occurs around the apex of the tooth with necrotic pulp. Its cause is a bacterial infection that occurs in the root canal system, where bacteria and their by-products are responsible for the establishment of the process and its progression to the periapical tissues. ${ }^{1}$ The established extraradicular lesions can be classified as symptomatic and asymptomatic apical periodontitis, depending on the virulence of the infectious agent and the host defense.

Asymptomatic or chronic periodontitis is most often represented by granulomas and periapical cysts. The progression of the lesion may lead to root and alveolar bone resorption, destruction of the periodontal ligament and development of granulation tissue, where radiographic examination is an important diagnostic aid. . $3,4^{2}$

Conventional endodontic treatment is always the first-line therapy. However, there are situations in which there is no reversion of the lesion, with continuation of the inflammatory process, and surgical intervention becomes necessary. The failure of this conventional treatment can be 
explained by the persistence of the inflammatory process due to the presence of microorganisms in the form of biofilms, and thus apical periodontitis is a lesion induced by biofilm. ${ }^{5}$

Biofilms are biological communities, organized into structured, coordinated and functional communities. The related bacteria have slow metabolism and high resistance and virulence due to phenotypic changes. The microorganisms present and their by-products have the ability to maintain, on their own, the inflammatory process. Thus, it is not only important to know the nature and role of this biofilm, but also to understand the functional capacity of the immune system against attacks by these microorganisms. Among the various cells that participate in immune responses, little attention has been paid to dendritic cells (DCs) and their presence in asymptomatic apical periodontitis. DCs are important cells of the immune system, having the function of capturing microorganisms that are harmful to the individual and presenting them to T or B lymphocytes, initiating a cascade of inflammatory reactions.

The role of dendritic cells in the progression of apical periodontitis has not been fully understood. The finding of these cells by scanning electron microscopy (SEM) in two clinical cases of endodontic surgery has drawn attention to this group to these cells. The purpose of this paper was to re-discuss apical periodontitis and apical biofilm and their possible relationship to dendritic cells.

\section{Apical periodontitis}

There are numerous periapical pathologies that develop as a result of the extent of pulpal inflammation and subsequent tissue necrosis. Periapical invasion by microorganisms from pulpal necrosis establishes inflammation at the level of the periodontal ligament. ${ }^{6}$ Upon reaching the apical region, the pathogens stimulate inflammatory and immunological responses in the periapical tissues, giving rise to apical periodontitis. Thus, periapical disease is a biological response to the presence of infection in the root canal and sometimes in the periapex.

Periapical lesions are characterized by inflammation and/or infection of the periapical region, being a natural biological response to different chemical, physical and microbiological agents. The microorganisms arrive at the periapex due to the infection of the dental pulp, that progresses apically. In this region, they establish and stimulate inflammatory/immunological responses, which can result in several types of periapical pathologies.

The action of microorganisms, enzymes, toxins, metabolic products, cellular constituents and inflammatory mediators, associated with the degree of virulence and host responses, determine the different pathologies that reach the root apex. ${ }^{2,6}$ Symptomatic apical periodontitis is associated with very virulent microorganisms and/or less resistant host and with weakened defenses; asymptomatic apical periodontitis is related to the microorganisms of low virulence and/or to a more resistant host. ${ }^{2,7}$

Asymptomatic apical periodontitis is a type of periapical pathology caused by etiological agents of endodontic origin and characterized by inflammation and destruction of the periapical tissues, through cellular and molecular mechanisms. These events result in the formation of a biological barrier called periapical lesion. ${ }^{8,9}$ These lesions are histologically called abscesses, granulomas or apical cysts. ${ }^{3}$ Due to their asymptomatic development, these lesions are basically revealed radiographically, and imaging tests are important tools for the assessment of periapical conditions..$^{10}$ Root resorption, periodontal ligament destruction, alveolar bone resorption and granulation tissue development are common. Most periapical inflammatory lesions of endodontic origin are periapical granulomas and root cysts, where these are transitions of the same pathological lesion, one of which may be transformed into the other.

In necrotic teeth and with periapical lesions which are visible radiographically, microorganisms inhabit the entire canal system, including the main canal and lateral, accessory and secondary canals, dentinal tubules, apical delta and foramen, regions of resorption in the cementum and adjacent periapical tissues. ${ }^{8}$

Microorganisms are the main etiological agents of persistent periapical lesions. They can invade the periapical tissues and develop an infectious process that is difficult to treat because they are 
able to develop mechanisms that allow them to adapt to the tissues and their invasion to the host defense systems. One of the main mechanisms is represented by a biofilm arrangement. ${ }^{11}$

\section{Biofilm}

Biofilm can be defined as a community of microorganisms adhered to a substrate - organic or inorganic - and incorporated in an exopolysaccharide matrix. ${ }^{12,13}$ This population of thin layers of microorganisms, such as bacteria, fungi and protozoa, needs the so-called planktonic microorganisms, which can be free-floating when in an aqueous environment. They are essential for the formation of biofilm. ${ }^{14}$

Pinchiari ${ }^{5}$ reported that the behavior of microorganisms in biofilms makes them much more resistant, mainly through the gel state and the structure of the polysaccharide matrix, which limits host defense molecules, phagocytic cells and also antimicrobial agents access. In this biofilm, there is a predominance of rods, spirochetes and filamentous bacilli, which when established in periradicular lesions, may lead to extraradicular infection. ${ }^{5}$

It is possible to observe bacterial organisms, in the form of biofilms, adhered to the canal walls in the more advanced stages of the infectious process present inside the root canal system. For this reason, there is a current trend that apical periodontitis may be a disease induced by biofilms. Bacteria organized in biofilms would represent a source of persistent tissue aggression, being more related to the chronic conditions of periapical pathologies. ${ }^{15}$

The organization and location of the bacteria, and their high resistance to host defense mechanisms and to the chemical and mechanical action of the endodontic treatment could explain therapeutic failure. ${ }^{5}$ In addition, the larger the periapical lesion, the more complex and diverse is the microflora that infects the root canal system ${ }^{15}$ A decrease of 9 to $13 \%$ of chances of an endodontic success has been reported when there is a periapical lesion evidenced by radiography. ${ }^{15}$

To date there is no definitive answer for the early detection of extraradicular biofilm in a given case. However, one should be aware of the persistence of a periapical lesion associated with an endodontically treated tooth. It is known that bacteria organized in biofilms adhered to the dentin walls or in areas of difficult access are extremely difficult to eliminate, and may even require special eradication strategies. . $^{12,14,16}$

In the quest for lesion resolution, numerous cell types are involved in the repair process. Inflammatory cells are essentially protective but can also cause damage to periodontal tissues in persistent and unregulated activation. ${ }^{4,16,17}$

As for immunity, adaptive or acquired immunity is specific to the antigen and serves to improve mechanisms of protection of innate immunity. Protective responses are acquired or learned as a consequence of some experience. Adaptive immunity includes antigen-specific lymphocytes ( $\mathrm{T}$ and $\mathrm{B}$ cells) and their products, which include inflammatory chemokines and antibodies, resulting in an exaggerated inflammatory response (immune inflammation) to eliminate infection. ${ }^{18}$

Lymphocytes, monocytes/macrophages and neutrophils are the major immunological cells reported in apical lesions, whereas mast cells are found in smaller numbers. In an analysis by Cavalla et al., ${ }^{4}$ lymphocytes represented the main cell population among these cells, comprising $49.57 \%$ of the total cells. The mast cells represented the second most frequent cell population, corresponding to $31.42 \%$ of the total cells. Monocytes/macrophages were $13.67 \%$, neutrophils $9.78 \%$, and dendritic cells $8.45 \%$, while $6.81 \%$ of cells in apical lesions were activated dendritic cells. Dendritic and monocytic cells are closely associated with severe inflammatory conditions. ${ }^{4}$

\section{Dendritic cells and apical periodontitis}

Dendritic cells (DCs), bone-marrow-derived leukocytes, are the most efficient antigen-presenting cells due to their ability to capture, process and present these antigens to $\mathrm{T}$ lymphocytes, thus regulating the adaptive immune response by activating $\mathrm{T}$ lymphocytes as antigen-presenting cells. ${ }^{16,17,19,20}$ These cells were reported by Steinman for the first time when a population of DCs was found in the spleen. It 
was later discovered that DCs existed in all lymphoid tissues and in most non-lymphoid tissues. ${ }^{16}$

It was formerly believed that the major antigenpresenting cells of the immune system were macrophages, because they were more abundant, distributed throughout the body and possessed antigen capacity. The reason for this was that DCs are rare and that they had been hardly studied at the time. However, as this was overcome, it was also accepted that DCs were the hosts of "professional" antigens. ${ }^{16}$

There are two maturation stages of DCs according to their ability to stimulate $\mathrm{T}$ cells. The first stage is like inactivated or immature cells. The second stage is like activated or mature cells. At the immature cell stage, DCs are scattered throughout the body in non-lymphoid organs, where they are specialized for the capture and processing of antigens. On the other hand, activated DCs migrate to drain the lymph nodes, where they are able to stimulate T cells. ${ }^{21}$

The morphological characteristics that define mature DCs are the various membranes that extend out from the cell body and the abundant intracellular structures that are associated with antigen processing, including Birbeck's endosomes, lysosomes and granules, and the presence or absence of some molecules on the cell surface. ${ }^{16}$

DCs are potent regulators of the immune system and their function is divided into three categories that involve the presentation of antigens: the presentation of antigens and activation of T cells; a not wellestablished category suggesting that DCs induce and maintain immunological tolerance; and the maintenance of immune memory in conjunction with B cells. ${ }^{16,17}$

DCs process and present antigens to activate CD4 + and CD8 + T cells, with naive T cells activated only by them. The origin of these immature antigenpresenting cells is given in the bone marrow and migrates throughout the body. These immature cells become inactive waiting to interact with invading pathogens or other foreign bodies, as it has the primary function of capturing antigens. If a lesion occurs in the body that is associated with inflammation, DCs are attracted to the area of inflammation and internally capture and process the antigens for presentation on the cell surface to stimulate CD4 + helper T cells. ${ }^{16}$

DCs are divided according to where they are produced and their function: plasmacytoids, myeloids and follicles. Plasmocytes are subtypes of DCs formed in the bone marrow that are especially related to both innate and adaptive immune responses. Myeloid subtypes also originate in the bone marrow and are located in the blood and tissues of organs such as the heart and kidneys. Their function is to identify and eliminate viruses, bacteria or worms through the activation of T lymphocytes. The follicular subtypes are formed in the lymph nodes and activate the B lymphocytes, also responsible for eliminating various types of microorganisms. ${ }^{16,17}$ In lining epithelium, DCs are also known as Langerhans cells. ${ }^{22}$

Periapical lesion tissues are infiltrated by different inflammatory cells, including antigen-presenting cells such as DCs and macrophages, which play an important role in the activation and function of $\mathrm{T}$ cells. DCs in periapical inflammatory lesions are composed of at least two subpopulations that can be distinguished on the basis of ultrastructure and phenotype. These populations may differ in lineage, state of maturation/differentiation/activation, and/ or function. ${ }^{20}$ However, even though macrophages and DCs activate T cells locally, DCs are the only ones responsible for the initiation of the immune response through the activation of naive cells in regional lymphoid tissues. ${ }^{23}$

A study was performed to test if local antigen presentation from DCs to T cells is involved critically in immunological responses within radicular granulomas. The results suggested that mature and activated DCs were mainly distributed and acted as antigen presentation against $\mathrm{T}$ cells in lymphocyterich areas of radicular granulomas. ${ }^{20}$

Another study evaluated periapical inflammatory lesions and observed an association between inflammation and immune response, which was demonstrated by the lymphocytes being part of the inflammatory response. Interstitial DCs detected by CD34 immunostaining are cells that initiate the immune response involved in the pathogenesis of periapical lesions. ${ }^{1}$ 
We analyzed the root apices of teeth 11, 12 and 22 by SEM, after performing apicoectomy due to the failure of conventional endodontic treatment and the persistence of the apical lesion after 6 months follow-up. The fragments of the teeth were fixed, dehydrated and sent to processing for analysis by SEM. The three apices were initially visualized at $60 \mathrm{x}$ magnification, thus obtaining a general appearance of each. The apical surfaces were then analyzed at increasing magnification, which allowed the evaluation of areas of biofilms and morphological aspects of microorganisms present in the area, and the determination of the presence of inflammatory cells as well. The following sequence of images (Figures 1, 2, 3 and 4) shows the findings referring to tooth 22 . Figure 5 shows another case of apicoectomy with SEM image of a dendritic cell.

The presence of extraradicular biofilm on the external surface of the root apex, even after the endodontic interventions performed, leads to the practical confirmation of all that has been studied about the possible causes of persistence of the periapical lesions being related to this biofilm. In addition to the variety of microorganisms present in the biofilm, cells of the inflammatory process could be observed, including the presence of DCs, suggesting that, due to its already described characteristics, they could be related to the persistence of the inflammatory process.

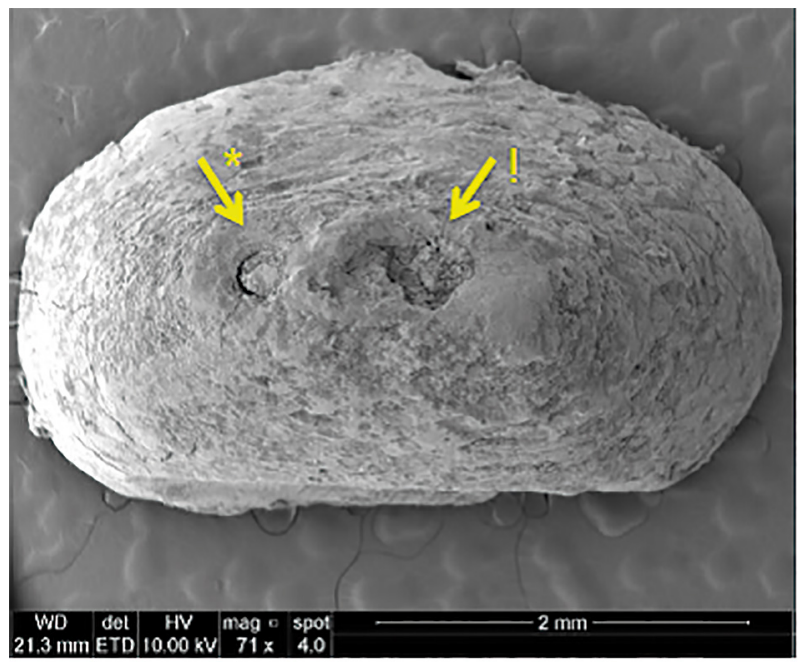

Figure 1. SEM demonstrating the general appearance of the root apex - visualization of the main foramen $\left({ }^{*} \rightarrow\right)$ and foramina $(! \rightarrow)$.
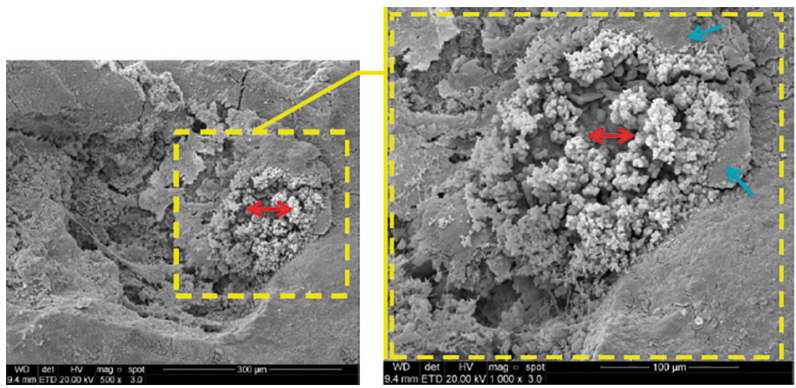

: Areas of resorption - presence of Howship lacunae. $\longleftrightarrow$ : Multispecies extraradicular biofilm

Figure 2. SEM at 500x and SEM at 1000x indicating both multispecies microbial biofilm and areas of resorption with the presence of Howship lacunae.
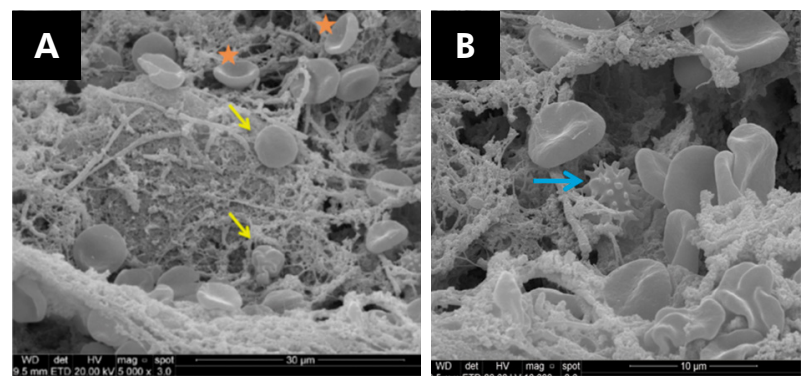

th: Image suggestive of erythrocyte - biconcave disc. $\longrightarrow$ : dendritic cell

Figure 3. SEM at 5000x demonstrating the presence of neutrophils (A) trapped in the multispecies extraradicular biofilm mesh. (B) SEM at 10,000x.
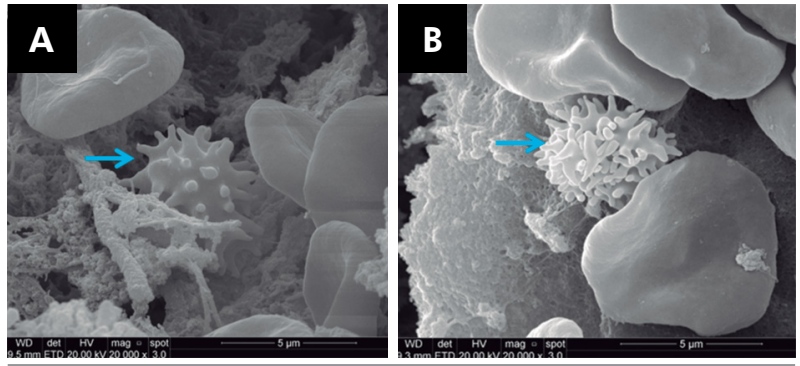

Figure 4. (A) SEM at 20,000x. (B) Image suggestive of a second dendritic cell in the same apex (20,000x).

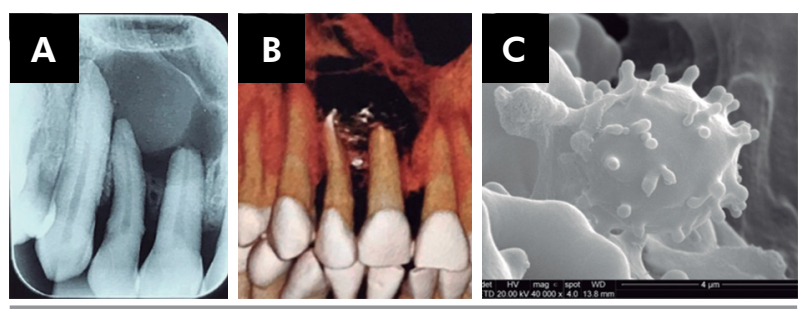

Figure 5. Another case suggesting the presence of a dendritc cell. (A) Periapical radiograph; (B) Dental tomography; (C) SEM at $40,000 x$. 


\section{Conclusion}

On the basis of this review, we can conclude the following points:

a. Apical periodontitis is strongly related to the presence of biofilm;

b. The behavior of microorganisms in biofilms makes them much more resistant and virulent. Identifying the presence of a microbial biofilm after endodontic treatment and its relation to the persistence of periapical lesions is important for understanding the possible causes of endodontic failure;

c. DCs are important cells of the immune system, having the function of capturing harmful

\section{References}

1. Berar AM, Bondor Cl, Matroş L, Câmpian RS. Radiological, histological and immunohistochemical evaluation of periapical inflammatory lesions. Rom J Morphol Embryol. 2016;57(2):419-25.

2. Estrela C, Figueiredo JAP. Endodontia: princípios biológicos e mecânicos. Porto Alegre: Artes Médicas; 2001.

3. Ricucci D, Russo J, Rutberg M, Burleson JA, Spångberg LS. A prospective cohort study of endodontic treatments of 1,369 root canals: results after 5 years. Oral Surg Oral Med Oral Pathol Oral Radiol Endod. 2011 Dec;112(6):825-42. https://doi.org/10.1016/i.tripleo.2011.08.003

4. Cavalla F, Reyes M, Vernal R, Alvarez C, Paredes R, García-Sesnich J et al. High levels of CXC ligand 12/Stromal cell-derived Factor 1 apical lesions of endodontic origin associated with mast cell infiltration. J Endod. 2013;39(10):1234-9. https://doi.org/10.1016/i.joen.2013.06.020

5. Pinchiari, RR. Aspectos relevantes relacionados ao biofilme perirradicular. 2007. 58 f.Monografia (Especialização em Endodontia) - Associação Paulista de Cirurgiões Dentistas, Regional Santo André; 2007.

6. Estrela C. Ciência endodôntica. Porto Alegre: Artes Médicas; 2004

7. Moura AAM, Davidowiicz H, Dias LP, Bardauil MRRS. [Assymptomatic apical periodontitis: clinical report]. Rev Inst Ciênc Saúde. 2007;25(4):463-8. Portuguese.

8. Peters LB, Wesselink PR, Moorer WR. Penetration of bacteria in bovine root dentine in vitro. Int Endod J. 2000;(33):28-36. https://doi.org/10.1046/j.1365-2591.2000.00268.x

9. Nair PN. Pathogenesis of apical periodontitis and the causes of endodontic failures. Crit microorganisms and presenting them to $\mathrm{T}$ or B lymphocytes;

d. DCs are associated with local defense reactions as stronger antigen-presenting cells;

e. The presence of DCs in an periapical lesion could be an indication of the severity of the lesion, with a constant presence of antigen in the periradicular region.

Although understanding the role of DCs in the human body has advanced in the last decades, little has been addressed in relation to its presence in asymptomatic apical periodontitis. Further studies are warranted to better understand the characteristics of these cells, their function in the immunological process and their use as a therapeutic ally.
Rev Oral Biol Med. 2004 Nov;15(6):348-81. https://doi.org/10.1177/154411130401500604

10. Pasler AF. Radiologia odontológica. Rio de Janeiro: Medsi; 1999.

11. Bowden GH, Hamilton IR. Survival of oral bacteria. Crit Rev Oral Biol Med. 1998;9(1):54-85. https://doi.org/10.1177/10454411980090010401

12. Nair PN. On the causes of persistent apical periodontitis: a review. Int Endod J. 2006 Apr;39(4):249-81. https://doi.org/10.1111/j.1365-2591.2006.01099.x

13. Narayanan LL, Vaishnavi C. Endodontic microbiology. J Conserv Dent. 2010 Oct;13(4):233-9.

14. Svensäter $G$, Bergenholtz G. Biofilms in endodontic infections. Endod Topics, 2004;9(1):27-36. https://doi.org/10.1111/j.1601-1546.2004.00112.x

15. Chandra A. Discuss the factor that affect the outcome of endodontic treatment. Aust Endod J. 2009 Aug;35(2):98-107. https://doi.org/10.1111/j.1747-4477.2009.00199.x

16. Wieder E. Dendritic cells: a basic review. Vancouver: International Society for CellularTherapy; 2003.

17. Durack C, Patel S. Cone beam computed tomography in endodontics. Braz Dent J. 2012;23(3):179-91. https://doi.org/10.1590/S0103-64402012000300001

18. Hahn CL, Liewehr FR. Update on the adaptive immune responses of the dental pulp. J Endod. 2007 Jul;33(7):773-81. https://doi.org/10.1016/i.joen.2007.01.002

19. Mittelbrunn M, Martínez del Hoyo G, López-Bravo M, Martín-Cofreces NB, Scholer A, Hugues S et al. Imaging of plasmacytoid dendritic cell interactions with T cells. Blood. 2009 Jan;113(1):75-84. https://doi.org/10.1182/blood-2008-02-139865 
Figueiredo JAP, Machado AM, Oliveira VP, Hartmann R, Waltrick SBG, Borba MG et al.

20. Kaneko T, Okiji T, Zhao L, Esgeurra R, Suda $\mathrm{H}$. Heterogeneity of dendritic cells in rat apical periodontitis. Cell Tissue Res. 2008 Mar;331(3):617-23. https://doi.org/10.1007/s00441-006-0313-2

21. Kopitar AN, Ihan Hren N, Ihan A. Commensal oral bacteria antigens prime human dendritic cells to induce Th1, Th2 or Treg differentiation. Oral Microbiol Immunol. 2006 Feb;21(1):1-5. https://doi.org/10.1111/j.1399-302X.2005.00237.x
22. Santos LC, Ramos EA, Gurgel CA, Santana EJ, Santos JN. Immunohistochemical detection of Langerhans cells in dental granulomas and radicular cysts. J Mol Histol. 2007 Jun;38(3):201-5. https://doi.org/10.1007/s10735-007-9088-3

23. Colic M, Gazivoda D, Vasilijic S, Vucevic D, Lukic A. Production of IL-10 and IL-12 by antigen-presenting cells in periapical lesions. J Oral Pathol Med. 2010 Oct;39(9):690-6. https://doi.org/10.1111/j.1600-0714.2010.00925.x 